\title{
Phenotypic Expression of erm Gene Among Staphylococcus aureus
}

GAURAV DALELA, ATUL VIJAY, MANOJ JOSHI

\begin{abstract}
Introduction: The increasing frequency of MRSA infections and rapidly changing patterns in antimicrobial resistance, led to renewed interest in the use of macrolide lincosamide- streptogramin B (MLSB) antibiotics to treat such infections.
\end{abstract}

Aim: To assess the prevalence of phenotypic expression of inducible resistance for clindamycin due to expression of erm genes, in clinical isolates of Methicillin resistant Staphylococcus aureus from various clinical samples using modified D test.

Materials and Methods: A total of 101 Methicillin resistant Staphylococcus aureus (MRSA) strains were included for induction tests which utilize closely approximated erythromycin, clindamycin and azithromycin discs (modified
$\mathrm{D}$ test); the flattening or indentation of the clindamycin zone of inhibition adjacent to the erythromycin and / or azithromycin disk indicates inducible MLSB (macrolide lincosamide- streptogramin B) resistance.

Results: Among the 101 clinical isolates, 37 (36.63\%) isolates shows $D$ test positive using Erythromycin, Clindamycin and Azithromycin combination. Inducible resistance to clindamycin using azithromycin was found in $5.94 \%$ isolates which was the major achievement of the study, which will be confirmed by genotyping in future.

Conclusion: D-test should be performed on all MRSA isolates, to avoid erroneous reporting resulting in treatment failure, a partial modification in the $D$ test can be made using azithromycin as it was helpful in our study, must be confirmed using genotyping.

\section{INTRODUCTION}

Staphylococcus aureus (S. aureus), common aetiology of both community and hospital acquired infections, causes minor skin infections to life threatening conditions such as endocarditis, pneumonia and septicaemia, having increased antimicrobial drug resistance which is one of the major concerns [1]. Prevalence rate of Methicillin resistant $S$. aureus (MRSA) has dramatically increased in recent years as it varies with geographical location and bacterial species $[2,3]$. For MRSA infection, vancomycin considered as drug of choice, however vancomycin usage is associated with considerable side effects and cost as well as overuse of vancomycin has led to the emergence of resistant strains with reduced susceptibility [4].

In the past decades MRSA, emerged as prevalent pathogen for community acquired infections (CA-MRSA), unlike hospital acquired MRSA, the CA-MRSA are sensitive to drugs other than vancomycin, such as, ciprofloxacin, trimethoprim sulphamethoxazole and clindamycin (CD) [5]. The increasing frequency of MRSA infections and rapidly changing patterns in antimicrobial resistance, led to renewed interest in the use of macrolide lincosamide - streptogramin B (MLSB) antibiotics to treat such infections [6].

Clindamycin belongs to the macrolide, lincosamide and streptogramin B (MLSB) family, act through inhibition of protein synthesis, resistance may be expressed through ribosomal target site modification (macrolide-lincosamidestreptogramin B [MLSB] resistance; usually encoded by erm A or erm C) cause production of methylase enzymes (methylation of the 23S rRNA) reduces binding of the drug to the rRNA target, macrolide efflux pump (encoded by msrA) and enzymatic antibiotic inactivation [7]. Mechanism of ribosomal target modification causes resistance either constitutive or inducible, if the erm genes are consistently expressed, isolates shows in vitro resistance to erythromycin $(E), C D$, and to other members of MLSB, known as constitutive resistance phenotype (cMLSB). In case of inducible resistance, the erm genes require an inducing agent 
to express resistance to CD (iMLSB). Erythromycin acts as a strong inducer of methylase synthesis. These isolates known as inducible resistance phenotype (iMLSB) show in vitro resistance to $E$ and are susceptibility to CD. CD therapy in this phenotype can lead to clinical failure [8-11]. S. aureus also have isolated macrolide resistance because of the presence of an efflux pump, the MS phenotype (resistance to erythromycin, inducible resistance to streptogramins and susceptibility to clindamycin), encoded by the msrA gene [12]. Clindamycin therapies can be safely given in infections with this phenotype without the risk of clinical failure. Therefore, it is important to differentiate these two mechanisms of resistance.

Phenotypic detection of inducible resistance can be made by double disk diffusion test (D-test), a distorted 'D-Shaped' zone of inhibition around clindamycin if an erythromycin disc is placed adjacent. D-test is a simple, reliable, inexpensive, sensitive, specific and easy to interpret test [13]. Low levels of Erythromycin resistance is the most effective inducers of iMLSB resistance [14]. Molecular markers for the erm genes are presently available, but costly and inconvenient for daily use. Thus, present study was done to detect the inducible clindamycin resistance in various clinical isolates of $S$. aureus by the disc diffusion induction test (modified $D$ test) along with azithromycin.

\section{MATERIALS AND METHODS}

The present study was conducted for a period of eight months from July 2013 to February 2014 and included a total of 101 non duplicate, consecutive MRSA isolates of S.aureus from the samples of vaginal swab, urine, pus, throat swab, skin swab etc. from Department of Microbiology, Jhalawar Medical College and Hospital, Jhalawar, Rajasthan.

\section{Inclusion Criteria}

Staphylococcus aureus isolates resistant to Cefoxitin were included in the study.

\section{Exclusion Criteria}

Isolates sensitive to cefoxitin were not included in the study.

\section{Study Design}

The Staphylococcus aureus strains were identified by using standard identification bacteriological procedures [15]. Antibiotic susceptibility tests were performed using KirbyBauer disc diffusion method. Methicillin resistance was detected by using a $30 \mu \mathrm{g}$ cefoxitin disc. Control strain Staphylococcus aureus ATCC 25923 was used. To identify the iMLSB phenotype, the D-test was performed. A lawn culture of the isolate which was adjusted to $0.5 \mathrm{McF}$ arland's concentration was made on a Mueller Hinton agar plate and discs of CD $(2 \mu \mathrm{g}) \mathrm{E}(15 \mu \mathrm{g})$ and AZM $(30 \mu \mathrm{g})$ were placed at a distance of $20 \mathrm{~mm}$ (centre to centre), along with routine antibiotic susceptibility testing [16]. The disc diffusion test, based on the D test, showed six phenotypes -

1. Constitutive Resistance (cMLSB Phenotype): Resistant to all E, AZM and CD.

2. D Positive AZM (iMLSB Phenotype): Inducible resistance to Clindamycin was manifested by flattening or blunting of the CD zone adjacent to AZM disc, giving a D shape.

3. D Positive E (iMLSB Phenotype): Inducible resistance to Clindamycin was manifested by flattening or blunting of the $\mathrm{CD}$ zone adjacent to $\mathrm{E}$ disc, giving a $\mathrm{D}$ shape.

4. D Positive AZM and E (iMLSB Phenotype): Inducible resistance to Clindamycin was manifested by flattening or blunting of the CD zone adjacent to E \& AZM disc.

5. D Negative (MSB Phenotype): No flattening of the CD zone; Resistant to both E\& AZM but susceptible to CD.

6. Sensitive (Phenotype): Sensitive to all E, AZM and CL.

\section{RESULTS}

Among the 101 clinical isolates [Table/Fig-1-5] of Staphylococcus aureus, all the isolates were Methicillin resistant Staphylococcus aureus (MRSA) after susceptibility to cefoxitin. Of the 101 Staphylococcus aureus isolates, 37 (36.63\%) isolates shows D test positive using Erythromycin, Clindamycin and Azithromycin combination. Inducible resistance to clindamycin using azithromycin was found in $5.94 \%$ isolates [Table/Fig-6,7] was the major achievement

\begin{tabular}{|l|c|c|}
\hline Sample & Quantity & Percentage \\
\hline Vaginal Swab & 12 & $11.88 \%$ \\
\hline Urine & 32 & $31.68 \%$ \\
\hline PUS & 18 & $17.82 \%$ \\
\hline Throat Swab & 4 & $3.96 \%$ \\
\hline Skin Swab & 35 & $34.65 \%$ \\
\hline
\end{tabular}

of the study.

\section{DISCUSSION}

Clindamycin is a drug, useful for treating skin and soft tissue infections, less costlier than some of the newer agents that might be considered for these infections, having excellent tissue penetration, accumulates in abscess, not impeded by high bacterial burden at the infection site, and no renal dose adjustments is required. After intravenous therapy due to good oral absorption, it is an important option in outpatient therapy as well as for follow-up.

The increased prevalence of staphylococcal infections along with worsening of antimicrobial resistance has 


\begin{tabular}{|l|c|c|c|c|}
\hline $\begin{array}{l}\text { Name of } \\
\text { Antibiotic }\end{array}$ & Sensitive & $\%$ & Resistant & $\%$ \\
\hline Vancomycin VA & 101 & $100 \%$ & 0 & $0 \%$ \\
\hline Linezolid LZ & 101 & $100 \%$ & 0 & $0 \%$ \\
\hline Netilmicin NET & 91 & $90.99 \%$ & 10 & $9.01 \%$ \\
\hline Erythromycin E & 34 & $33.66 \%$ & 67 & $66.34 \%$ \\
\hline Clindamycin CD & 62 & $61.39 \%$ & 39 & $38.61 \%$ \\
\hline Azithromycin AZM & 46 & $45.54 \%$ & 55 & $54.46 \%$ \\
\hline Cotrimoxazole BA & 36 & $35.64 \%$ & 65 & $64.36 \%$ \\
\hline Augmentin AG & 34 & $33.66 \%$ & 67 & $66.34 \%$ \\
\hline Ceftriaxone CTR & 20 & $19.80 \%$ & 81 & $80.20 \%$ \\
\hline Ciprofloxacin CIP & 42 & $41.58 \%$ & 59 & $58.42 \%$ \\
\hline Gentamicin GM & 64 & $63.37 \%$ & 37 & $36.63 \%$ \\
\hline Doxycycline DO & 72 & $71.29 \%$ & 29 & $28.71 \%$ \\
\hline Nitrofurantoin NIT & 22 & $68.75 \%$ & 10 & $31.25 \%$ \\
\hline Amikacin AK & 75 & $74.26 \%$ & 26 & $25.74 \%$ \\
\hline Tobramycin TOB & 65 & $64.36 \%$ & 36 & $35.64 \%$ \\
\hline Cefixime CFM & 52 & $51.49 \%$ & 49 & $48.51 \%$ \\
\hline $\begin{array}{l}\text { Piperacillin + } \\
\text { Tazobacum PIT }\end{array}$ & 61 & $60.40 \%$ & 40 & $39.60 \%$ \\
\hline Ofloxacin OF & 39 & $38.61 \%$ & 62 & $61.39 \%$ \\
\hline Cefoxitin CX & 0 & $0 \%$ & 101 & $100 \%$ \\
\hline Cephelexin CN & 20 & $19.80 \%$ & 81 & $80.20 \%$ \\
\hline Table/Fg-2: & & & & \\
\hline
\end{tabular}

[Table/Fig-2]: Resistance and sensitivity pattern of Methicillin resistant Staphylococcus aureus (MRSA) in various clinical samples.

\begin{tabular}{|l|c|c|}
\hline Resistance (D Test) & D Test Result & Percentage \\
\hline $\begin{array}{l}\text { Constitutive (E-R, AZM-R, } \\
\text { CD-R), cMLSB }\end{array}$ & 33 & $32.67 \%$ \\
\hline $\begin{array}{l}\text { Inducible azithromycin (E-S, } \\
\text { AZM-R, CD-S), iMLSBazm }\end{array}$ & 6 & $5.94 \%$ \\
\hline $\begin{array}{l}\text { Inducible erythromycin (E-R, } \\
\text { AZM-S, CD-S), iMLSB e }\end{array}$ & 18 & $17.82 \%$ \\
\hline $\begin{array}{l}\text { Inducible both (E-R, } \\
\text { AZM-R, CD-S), iMLSBe.azm }\end{array}$ & 13 & $12.87 \%$ \\
\hline $\begin{array}{l}\text { Non inducible (E-R, AZM-R, } \\
\text { CD-S), MSB }\end{array}$ & 3 & $2.97 \%$ \\
\hline $\begin{array}{l}\text { Sensitive (E-S, AZM-S, CD-S) } \\
\text { [Table/Fig-3]: Distribution of constitutive resistance, inducible } \\
\text { resistance and sensitive isolates. }\end{array}$ & 28 & $27.72 \%$ \\
\hline
\end{tabular}

led to renewed interest in Clindamycin usage. The new guidelines for treatment of skin and soft tissue infections [17], recommended CD as a good choice, for empirical and therapeutic treatment for mild to moderate infections and a good alternative to penicillin allergic patients [18]; however, the guidelines also highlight the risk of therapeutic failure of using $C D$ in inducible resistant phenotype.

However, recent data indicate that treatment failure may
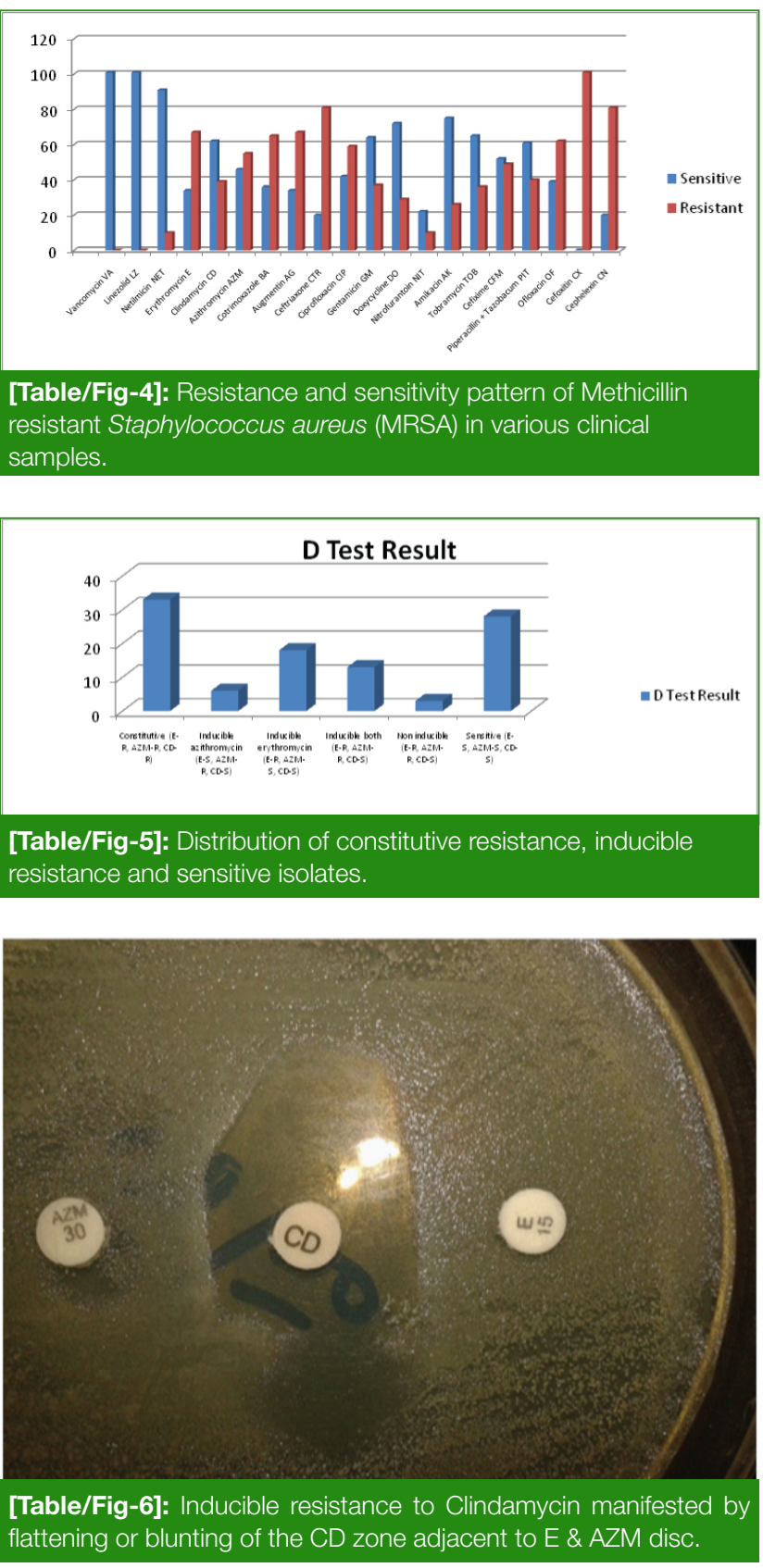

occur, in spite of in vitro susceptibility to $C D$, in the case of inducible MLSB resistance [19]. Accurate susceptibility data are important to avoid treatment failure. Hence, we have to follow the routine testing of Staphylococcal isolates for inducible clindamycin resistance as recommended in CLSI guidelines [20].

Of the total 101 isolates, 37(36.63\%) were of the iMLSB phenotype in the present study, which is similar to that reported by Santala GB et al., reported that 41 (32.5\%) of the 126 MRSA isolates were found to be of the iMLSB phenotype, and Fiebelkorn et al., who have reported 29\% iMLSB which is similar to our study [3,13]. Studies from 


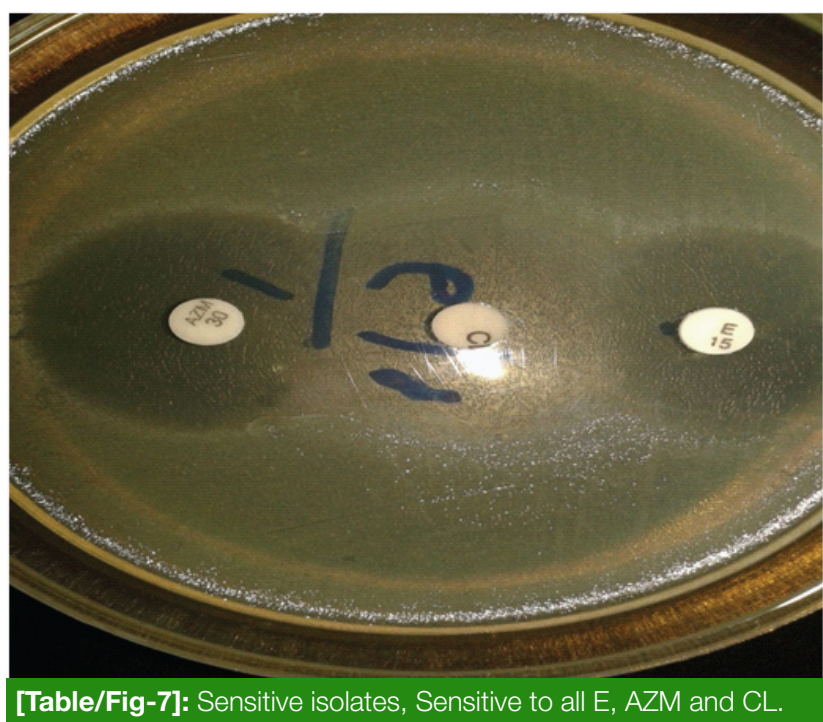

different parts of India have reported $30 \%$ to $64 \%$ of the MRSA isolates to be of the iMLSB phenotype [21].

In the present study, 33 (32.67\%) S.aureus strains were of the cMLSB phenotype, while Santala GB et al., [3] reported 25.39\% MRSA isolated having cMLSB phenotype. However, Gupta et al., [22] have reported $46 \%$ cMLSB resistance in MRSA isolates which is nearly similar to our study.

Three (2.97\%) S.aureus strains showed the MSB phenotype in the present study while Gadepalli et al., and Santala GB et al., have reported $12 \%$ and $15.65 \%$ of the MSB phenotype among the S.aureus strains. This low prevalence in our study was due to modification in the $D$ test by addition of azithromycin which identified $5.94 \%$ more strains as compared to other study which used only erythromycin [3, 20]. The addition of azithromycin needs further evaluation, by having more number of samples, genotyping of isolates that are iMLSB (only by azithromycin), and to confirm the significance of adding of the drug in $\mathrm{D}$ test.

The true incidence depends on the patient population studied, site of sample collection, the geographical region, and the hospital characteristics (nosocomial burden). Most of the studies have indicated a higher prevalence of constitutive resistance than inducible resistance in Staphylococcus aureus contrast to our study. The present study showed a higher incidence of iMLSB (36.63\%) as compared to cMLSB $(32.67 \%)$ in the S.aureus isolates, which was similar to the findings of studies conducted by Shantala GB et al.,[3], reported $24.89 \%$ strains of iMLSB and $18.26 \%$ strains of cMLSB while Mallick et al.,[21], who reported $18.6 \%$ strains of iMLSB and $3.8 \%$ strains of CMLSB.

Furthermore, the D-test must be performed on all Staphylococcal strains, isolated in the laboratory, as a routine test, whereas, most of the studies select only isolate that are
E resistant and CD susceptible for testing. The authors were concerned that if in the D-test addition of AZM will be made more chances of detection of iMLSB strains can be possible if genotyping study will confirm the use of AZM in the D test (modified D test), and also no delay is to be made for the detection of clindamycin resistance to ensure maximum clinical utility of the drug.

Definitive identification of production of erm gene is possible using molecular detection methods. However, the techniques required for the task of identifying the exact erm gene subtype responsible for phenotypic detection by $\mathrm{D}$ test for azithromycin (e.g. DNA probing, polymerase chain reaction, restriction fragment length polymorphism and isoelectric focusing) are available only at research facilities. Perhaps with the advent of gene chip technology in near future, the subtype identification of erm gene will be performed more routinely in our laboratory.

\section{CONCLUSION}

The implementation of the modified D-test (with addition of azithromycin), a simple, auxiliary method with routine antibiotic susceptibility testing, delineates inducible and constitutive clindamycin resistance. The high rates of occurrence of inducible resistance raise concerns that clindamycin treatment failures may occur with MRSA infection therefore ,early detection helps us to avoid treatment failures caused by truly clindamycin susceptible $S$. aureus.

\section{REFERENCES}

[1] Schito GC. The importance of the development of antibiotic resistance in Staphylococcus aureus. Clin Microbiol Infect. 2006; 12(Suppl) 1: 3-8.

[2] Rajaduraipandi K, Mani KR, Panneerselvam K, Mani M, Bhaskar M, Manikandan P. Prevalence and antimicrobial susceptibility pattern of methicillin resistant Staphylococcus aureus: a multicentre study. Indian J Med Microbiol. 2006; 24: 34-38.

[3] Shantala G B, Shetty AS, Rao RK et al. detection of inducible clindamycin resistance in clinical isolates of Staphylococcus aureus by the disc diffusion induction test. J Clin Diag Res. 2011; 5(1): 35-37.

[4] Smith TL, Pearson ML, Wilcox KL, Cruz C, Lancaster MV, Robinson-Dunn B, et al. Emergence of vancomycin resistance in Staphylococcus aureus. glycopeptide intermediate Staphylococcus aureus working group. N Eng J Med. 1999; 340: 493501.

[5] Naimi TS, LeDell KH, Como-Sabetti K, Borchardt SM, Boxrud DJ, Etienne J, et al. Comparison of community- and health-care associated methicillin resistant Staphylococcus aureus infection. JAMA. 2003; 290: 2976-84.

[6] Lertcanawanichakul M, Chawawisit K, Choopan A, Nakbud $\mathrm{K}$, Dawveera Kul K. Incidence of constitutive and inducible clindamycin resistance in clinical isolates of methicillin resistant Staphylococcus aureus. Walailak J Sci \& Tech. 2007; 4:155-63.

[7] Leclercq R. Mechanisms of resistance to macrolides and lincosamides: nature of the resistance elements and their clinical implications. Clin Infect Dis. 2002; 34: 482-92. 
[8] Lewis JS $2^{\text {nd }}$, Jorgensen $\mathrm{JH}$. Inducible clindamycin resistance in Staphylococci: should clinicians and microbiologists be concerned? Clin Infect Dis. 2005; 40: 280-85.

[9] Levin TP, Suh B, Axelrod P, Truant AL, Fekete T. Potential clindamycin resistance in clindamycin-susceptible, erythromycinresistant Staphylococcus aureus: report of a clinical failure. Antimicrob Agents Chemother. 2005; 49: 1222-24.

[10] Rao GG. Should clindamycin be used in treatment of patients with infections caused by erythromycin-resistant staphylococci? J Antimicrob Chemother. 2000; 45: 715.

[11] Drinkovic D, Fuller ER, Shore KP, Holland DJ, Ellis-Pegler R. Clindamycin treatment of Staphylococcus aureus expressing inducible clindamycin resistance. J Antimicrob Chemother. 2001; 48: 315-16.

[12] Delialioglu N, Aslan G, Ozturk C, Baki V, Sen S, Emekdas G. Inducible clindamycin resistance in Staphylococci isolated from clinical samples. Jpn J Infect Dis. 2005; 58:104-06.

[13] Fiebelkorn KR, Crawford SA, McElmeel ML, Jorgensen JH. Practical disk diffusion method for detection of inducible clindamycin resistance in Staphylococcus aureus and coagulase-negative staphylococci. J Clin Microbiol. 2003; 41: 4740-44.

[14] Yilmaz G, Aydin K, Iskender S, Caylan R, Koksal I. Detection and prevalence of inducible resistance in Staphylococci. J Med Microbiol. 2007; 56:342-45.
[15] Mandell, Douglas, and Bennett's Principles and Practice of Infectious Diseases, $7^{\text {th }}$ ed.

[16] Clinical and laboratory standards institute (CLSI).performance standards for antimicrobial disk susceptibility tests. Approved standard M2-A7, $11^{\text {th }}$ ed. 2005: 768-800.

[17] Stevens DL, Bisno AL, Chambers HF, Everett ED, Dellinger P, Goldstein EJ, et al. Practice guidelines for the diagnosis and management of skin and soft tissue infections. Clin Infect Dis. 2005; 41: 1373-406.

[18] Kasten MJ. Clindamycin, metronidazole, and chloramphenicol. Mayo Clin Proc. 1999; 74: 825-33.

[19] Chelae S, Laohaprertthisarn V, Phengmak M, Kongmuang U, Kalnauwakul S. Detection of inducible clindamycin resistance in Staphylococci by disc diffusion induction test. J Med Assoc Thai. 2009; 92(7):947-51.

[20] Gadepalli R, Dhawan B, Mohanty S, Kapil A, Das BK, Chaudhary $R$. Inducible clindamycin resistance in clinical isolates of Staphylococcus aureus. Indian J Med Res. 2006; 123:571-73.

[21] Mallick SK, Basak S, Bose S. Inducible clindamycin resistance in Staphylococcus aureus-A therapeutic challenge. J Clin Diag Res. 2009; 3:1513-18.

[22] Gupta V, Datta P, Rani H, Chander J. Inducible clindamycin resistance in Staphylococcus aureus: A study from North India. J Postgrad Med. 2009; 55:176-79.

\section{AUTHOR(S):}

1. Dr. Gaurav Dalela

2. Dr. Atul Vijay

3. Dr. Manoj Joshi

\section{PARTICULARS OF CONTRIBUTORS:}

1. Associate Professor and HOD, Department of Microbiology, RUHS College of Medical Sciences, Jaipur, Rajasthan, India.

2. Associate Professor and HOD, Department of Skin \& VD, Jhalawar Medical College and Hospital, Jhalawar, Rajasthan, India.

3. Professor, Department of Microbiology, Jhalawar Medical College and Hospital, Jhalawar, Rajasthan, India.

\section{NAME, ADDRESS, E-MAIL ID OF THE CORRESPONDING AUTHOR:}

Dr. Gaurav Dalela,

Associate Professor and HOD, Department of Microbiology, RUHS College of Medical Sciences, Jaipur - 302033,

Rajasthan, India.

E-mail: gauravdalela29@gmail.com

FINANCIAL OR OTHER COMPETING INTERESTS: None.
Date of Online Ahead of Print: Feb 29, 2016 Date of Publishing: Apr 01, 2016 